\title{
Changing hydroclimate dynamics and the 19th to 20th century wetting trend in the English Channel region of northwest Europe
}

\author{
Serena R. Scholz ${ }^{1} \cdot$ Richard Seager ${ }^{2} \cdot$ Mingfang Ting $^{2} \cdot$ Yochanan Kushnir $^{2} \cdot$ Jason E. Smerdon ${ }^{2} \cdot$ Benjamin I. Cook $^{2}$. \\ Edward R. Cook ${ }^{2}$. Seung Hun Baek ${ }^{3}$
}

Received: 19 November 2020 / Accepted: 21 September 2021

(c) The Author(s), under exclusive licence to Springer-Verlag GmbH Germany, part of Springer Nature 2021

\begin{abstract}
Northwestern Europe has experienced a trend of increasingly wet winters over the past 150 years, with few explanations for what may have driven this hydroclimatic change. Here we use the Old World Drought Atlas (OWDA), a tree-ring based reconstruction of the self-calibrating Palmer Drought Severity Index (scPDSI), to examine this wetting trend and place it in a longer hydroclimatic context. We find that scPDSI variability in northwestern Europe is strongly correlated with the leading mode of the OWDA during the last millennium (1000-2012). This leading mode, here named the 'English Channel' (EC) mode, has pronounced variability on interannual to centennial timescales and has an expression in scPDSI similar to that of the East Atlantic teleconnection pattern. A shift in the EC mode from a prolonged negative phase to more neutral conditions during the 19th and 20th centuries is associated with the wetting trend over its area of influence in England, Wales, and much of northern continental Europe. The EC mode is the dominant scPDSI mode from approximately 1000-1850, after which its dominance waned in favor of the secondary 'North-South' (NS) mode, which has an expression in scPDSI similar to that of the winter North Atlantic Oscillation (NAO). We examine the dynamical nature of both of these modes and how they vary on interannual to centennial timescales. Our results provide insight into the nature of hydroclimate variability in Europe before the widespread availability of instrumental observations.
\end{abstract}

Keywords Hydroclimate $\cdot$ Paleoclimate $\cdot$ Precipitation $\cdot$ Drought $\cdot$ Europe

\section{Introduction}

Changes in hydroclimate are particularly influential on human societies, as droughts and floods affect agricultural production, transportation, food security, economic stability, and can threaten lives and property. Extended periods of wet conditions have received comparatively less attention than droughts, but also have the capacity to severely disrupt agriculture and society: either through direct deluge of crop fields (e.g. Posthumus et al. 2009), or by lulling society into a false sense of water security ahead of renewed scarcity

Serena R. Scholz

srscholz@umich.edu

1 Department of Earth and Environmental Sciences, University of Michigan, Ann Arbor, MI, USA

2 Lamont-Doherty Earth Observatory of Columbia University, Palisades, NY, USA

3 Yale University, New Haven, CT, USA (e.g. Fye et al. 2003; Cook et al. 2007). In England and Wales, there is considerable concern that increasing precipitation and rising sea levels will increase flood risk in the coming decades, leading to economic and social challenges (e.g. Hall et al. 2005). While evidence for increasing flood risk in the United Kingdom points to rises in precipitation intensity (e.g. Cotterill et al. 2021), this could be exacerbated by any shift towards a wetter mean climate.

Studies of historical and modern European hydroclimate have found that while southern Europe and the Mediterranean have become increasingly arid in the past century (Seager et al. 2019), much of northwestern Europe has experienced a significant upward trend in winter precipitation during the past 150 years. Long-term rain gauge records from Paris and Northern France (Slonosky 2002), river flow records from the Seine (Dieppois et al. 2013; Dieppois et al. 2016), and rain gauges in England and Wales (Wigley et al. 1984; Alexander and Jones 2000; Marsh et al. 2007), all show a positive trend in winter and early spring precipitation levels beginning in the mid-19th century. In Paris, the 
20th century included significantly more extreme wet years than previous centuries, and the winter of 2000/2001 was the wettest experienced in over 300 years (Slonosky 2002). Markonis et al. (2018) found that even within the context of the past millennium, this modern pluvial is particularly extreme in its longevity and spatial extent.

Human-induced climate change has been invoked to explain drying in the Mediterranean region (Seager et al. 2019) and may also contribute to the wet trend in the north: climate models project that precipitation at high latitudes will increase worldwide due to warming temperatures and intensification of the hydrologic cycle (Madakumbura et al. 2019; Cook et al. 2020). However, the wetting trend in northern Europe began in the late 19th century, before the advent of strong radiative forcing by rising greenhouse gases. It is therefore more likely to be caused by natural decadal and longer timescale climate variability, though there could be anthropogenic contributions as well.

European climate variability during the relatively recent instrumental period is strongly linked to the North Atlantic Oscillation (NAO), a fluctuation in the sea level pressure difference between the subtropical high (near the Azores) and the subpolar low (near Iceland), which influences the strength and latitude of the westerly flow over the North Atlantic and Europe (Hurrell 1995; Cassou et al. 2004; Hurrell and Deser 2009; Seager et al. 2010, 2020). The NAO is correlated with extreme precipitation events in the Mediterranean and northwestern Europe (Krichak et al. 2014) and can be connected to a range of other variables, including water availability and river discharges in the Middle East and the Iberian Peninsula (Cullen et al. 2002; Trigo et al. 2004) and wheat yields in Northern Africa and Europe (Anderson et al. 2019). However, the NAO does not explain the increasingly wet winters in northwestern Europe. Paris rain gauge records, which clearly show the increase in wintertime precipitation, were not found to correlate significantly with the NAO index (Slonosky 2002). A decrease in drought frequency in northern Europe in the most recent century was likewise not correlated with the NAO, nor with any other major climate indices such as the El Niño-Southern Oscillation (ENSO), or Atlantic Multidecadal Variability (AMV) (Sheffield and Wood, 2008). The causes of this 19th -to20th -century wetting trend in the regions around the English Channel therefore remain unclear.

The Old World Drought Atlas (OWDA, Cook et al. 2015) is a tree-ring based reconstruction of the self-calibrating Palmer Drought Severity Index (scPDSI) in Europe over the past two millennia. Importantly, the OWDA was constructed without explicitly calibrating on any known climate patterns or teleconnections, thus allowing for the independent examination of naturally occurring modes of hydroclimate variability. Recent studies of the OWDA have shown that its leading hydroclimate mode over Europe in the past is not consistent with the instrumental period NAO footprint, but instead consists of a spatially dominant anomaly over northwestern Europe with only weak anomalies elsewhere (Baek et al. 2020; Markonis et al. 2018). This mode has been linked to the torrential rains of the Great Famine of 1315-1317, and found to be correlated with the average scPDSI of northwest Europe (Baek et al. 2020). Due to its length, the OWDA provides an excellent opportunity to examine the behavior of these types of modes of variability, which cannot be clearly seen within the much shorter instrumental record.

The OWDA is tree-ring based, and therefore records soil moisture availability primarily in the boreal growing season, from late spring through the summer. However, the spring/ summer soil moisture also depends on lagged precipitation and temperature signals extending from the preceding boreal winter into the summer growing season (Baek et al. 2017). Because modes in the OWDA can therefore encompass variability across multiple seasons, care must be taken in their interpretation. The OWDA has nevertheless successfully been used to study winter-dominant phenomena like the winter NAO (Cook et al. 2019), showing that the dataset can provide an accurate record of climate in the winter/spring season as well as spring/summer.

In this study we further examine the leading modes of variability in the OWDA over the last millennium, in order to better understand how hydroclimate can vary over centuries. As in Baek et al. (2020), we find the leading mode over the entire last millennium has a dominant anomaly centered on the English Channel (hereafter called the English Channel or EC mode). The dominance of this mode over the millennium highlights that European climate has a rich variety of phenomena beyond the NAO. However, beginning in the mid-19th century, we find that the EC mode wanes in importance and the previous secondary mode becomes unusually dominant. This swap in the dominant expression of the two modes coincides with increasing wintertime precipitation in the EC mode's area of influence. We analyze the interannual to centennial variability of these modes, and show that this centennial scale shift in the EC mode may be related to the late 19th-century wetting trend over England, Wales and northern continental Europe.

\section{Data and methods}

The Old World Drought Atlas (OWDA) is a spatially resolved annual reconstruction of the self-calibrating Palmer Drought Severity Index (scPDSI) based on a network of treering records (Cook et al. 2015; https://www.ncdc.noaa.gov/ paleo-search/study/19419). The improved 'self-calibrating' PDSI method allows more accurate estimation of local hydroclimate variability, relative to the original PDSI formulation (Wells et al. 2004; van der Schrier et al. 2013). 
The OWDA data are arranged on an even $0.5^{\circ}$ latitude-longitude grid encompassing 5414 points across Europe and the Mediterranean from $1 \mathrm{BCE}$ to $2012 \mathrm{CE}$. Despite the availability of some reconstructed grid cells prior to 1000 $\mathrm{CE}$, our subsequent analyses only use the OWDA from 1000 to $2012 \mathrm{CE}$, as the loss of tree-ring records prior to that time reduces the spatial coverage considerably. In the most recent decades, the OWDA steadily transitions to include instrumental scPDSI records, but we use the entire modern period of the OWDA (up to 2012) in order to best place the modern climate variability in a long-term context.

scPDSI in the OWDA is a proxy for moisture availability in the vadose zone (the unsaturated region extending from the land surface to the top of the water table) during the growing season. Soil moisture is influenced by both precipitation and temperature, though precipitation is the more dominant influence. The OWDA is most strongly correlated with summertime precipitation across the entire domain, but large areas of northwestern Europe, Iberia, Northern Africa, Scandinavia and the Levant are also significantly correlated with wintertime precipitation (Fig. 1). The OWDA can therefore be used to investigate winter, spring and summer hydroclimate variability. Significant correlations between the OWDA and summertime temperature, particularly in southern Europe, are likely due to higher rates of evaporation.

Variables used herein, together with OWDA, are surface air temperature, precipitation, $500 \mathrm{hPa}$ geopotential heights, sea surface temperatures (SSTs), instrumental scPDSI, and indices of major Northern Hemisphere teleconnection patterns. Surface air temperature and precipitation data were obtained from the CRU 3.25 global temperature and precipitation grids (1901-2010, Harris et al. 2017, https://crudata.uea.ac.uk/cru/data/hrg/). Geopotential heights were obtained from the 20th Century Reanalysis Project (1854-2010, Compo et al. 2011, https:// www.psl.noaa.gov/data/20thC_Rean/). SSTs are from the NOAA ERSST v. 5 global SST dataset (1854-2010, Huang et al. 2017, https://www.ncdc.noaa.gov/data-access/marin eocean-data/extended-reconstructed-sea-surface-tempe rature-ersst-v5). The instrument-based van der Schrier scPDSI (vdS scPDSI, van der Schrier et al. 2013) was used for comparison with the OWDA scPDSI in the recent period (1901-2010). Indices of the NAO, East Atlantic
Fig. 1 Correlation between the raw OWDA values and CRU 3.25 temperature and precipitation grids, from 1950 to 2010 . Only values above the 0.05 significance level are shown, otherwise the point is uncolored. Some areas in Africa are not present in the OWDA (see Fig. 2 for the OWDA's spatial extent), these values are also uncolored

\section{a. JFMA Precipitation}

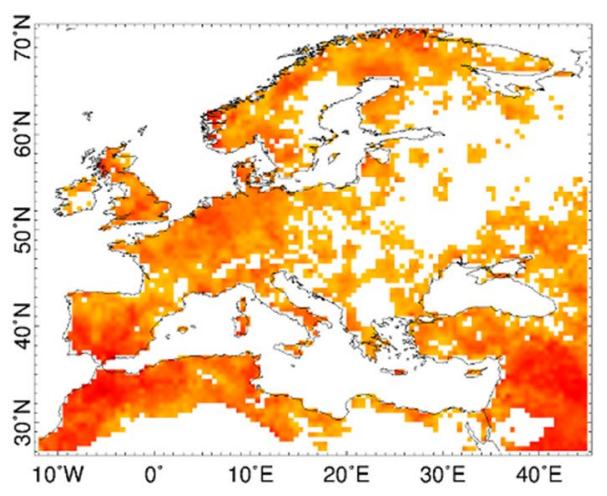

c. JFMA Temperature

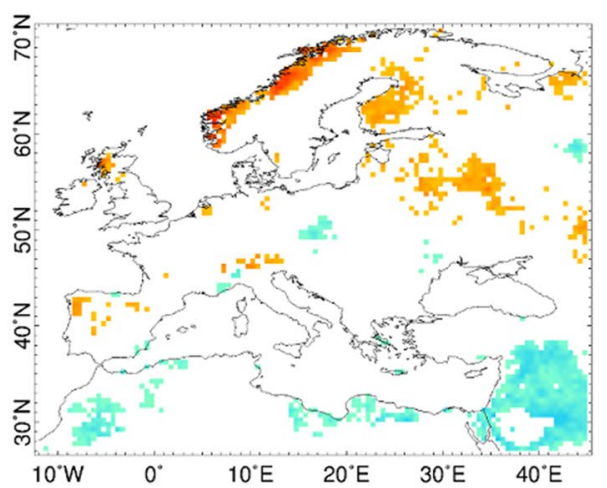

\section{b. MJJA Precipitation}

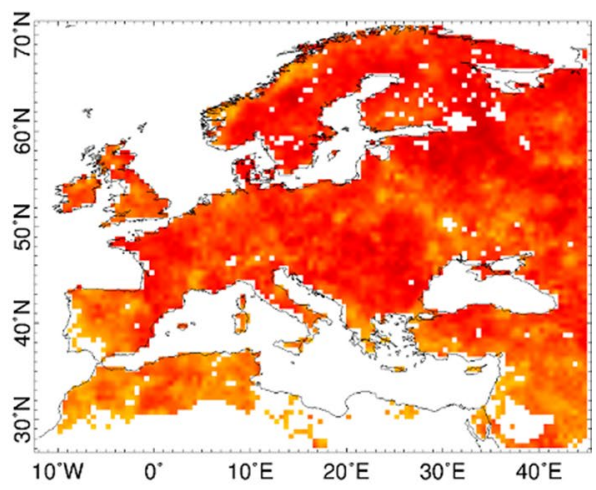

d. MJJA Temperature

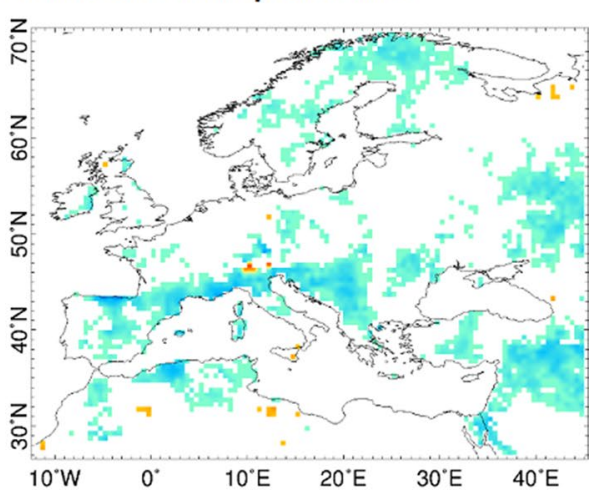

Correlation
$-1$
$-0.5$
0
0.5 
(EA), and Scandinavian (SCA) patterns used for examining teleconnections are from the NOAA-NCEP Climate Prediction Center (CPC, 1950-2010, https://www.cpc. ncep.noaa.gov/data/teledoc/telecontents.shtml). Analyses of instrumental and reanalysis data are conducted for two four-month seasons called winter/spring (January to April, JFMA) and spring/summer (May-July, MJJA). These extended seasons were chosen to show the clear seasonal differences between winter and summer results without needing to show three sets of maps for the more traditional 3-month seasons. To correspond to the time interval covered by the CPC indices, we perform analyses using instrumental and reanalysis data from 1950 to 2010 and then, for a check on robustness, repeat from 1900 to 1949.

Empirical Orthogonal Function (EOF) analysis was used to decompose the OWDA into modes of variability. This was done for the entire millennium (1000-2012) with the long-term mean removed, retaining the interannual to centennial timescale variability. EOF analysis was also conducted on a century-by-century basis to focus on interannual to decadal variability. This also allows us to observe any fluctuations in leading modes over time. EOFs were calculated on the covariance matrix with a cosine of latitude area weighting of the covariances and without rotation. The self-calibrating nature of the OWDA scPDSI means that the dataset is already normalized for local conditions (Wells et al. 2004), therefore we use the covariance rather than the correlation matrix in order to capture the areas with the highest amplitude of variability (as discussed in Dommenget and Latif (2002)). All modes were determined to be statistically distinct and outside of sampling error, as defined by North et al. (1982).

All results are presented with a significance level of 0.05 based on the corrected degrees of freedom that account for time series serial correlation. Corrected degrees of freedom were determined from autocorrelation estimates in the OWDA principal components, as well as in the instrumental and reanalysis data, using the method presented in Cook and Jacoby (1977):

$N^{\prime}=(N-2) \frac{\left(1-r_{1} r_{2}\right)}{\left(1+r_{1} r_{2}\right)}$

where $N$ is the number of observations, $r_{1}$ and $r_{2}$ are the autocorrelations of both timeseries at lag 1 , and $N^{\prime}$ is the corrected degrees of freedom. When correlating OWDA PC timeseries to fields, $r$ values for the fields were computed by taking the cosine-latitude weighted mean of $r$ values at lag 1 across the entire domain. This correction was also performed for regressions with the CPC indices for consistency. However, in this case the correction was found to be mostly insignificant due to small amounts of autocorrelation in the teleconnection timeseries.

\section{Results}

\subsection{The leading modes of ScPDSI variability in the OWDA over the last millennium}

EOF analysis of the OWDA over the period 1000-2012 yields similar results to those found by Baek et al. (2020) (EOF analysis of the entire domain, 1300-2012), and Markonis et al. (2018) (EOF analysis of central Europe, 992-2012). The first and second leading modes of the OWDA from 1000 to 2012 represent $15 \%$ and $10 \%$ of the variance, respectively. For the positive phase shown, the first mode has a positive (wet) anomaly centered over northwestern Europe, particularly the British Isles, northern France and Germany, and very high local explained variance in the same region (Fig. 2). Southern Scandinavia, particularly Sweden, is also positive. This feature is centered approximately over the regions surrounding the English Channel (EC), and we explicitly identify it here as the EC mode. Opposite sign anomalies are present over the southern Iberian Peninsula, northwestern Africa, and Greece and Turkey, but these are much weaker than the anomalies in northwestern Europe and do not explain much variance.

The timeseries of the EC mode (PC1, Fig. 2) has clear interannual, decadal and centennial variability. The 20 -year moving average has notable minima in 1460-1466, at the end of a long negative period, and another extended negative period centered around 1800 (Fig. 2a). After this, over the mid-to-late 19 th century and early 20 th century, the timeseries trends upward to a positive state.

In contrast to EOF1, the second mode has a negative (dry) anomaly centered over the Balkans, Turkey, and much of Eastern Europe (Fig. 2) in its positive phase, and a weaker positive (wet) anomaly over eastern Scandinavia and Russia, with the nodal line being nearly east-west. Local explained variance is highest in the Balkans and Turkey, but not as high as those explained by the EC mode in northwestern Europe. The timeseries of the second EOF (PC2, Fig. 2) does not have century-scale trends comparable to the EC, though it does have clear decadal timescale departures, including a large negative departure in the late 19th century. The 20-year moving average of the $\mathrm{PC} 2$ timeseries has notable maxima from 1358 to 1362 and 1862-1866, and minima in 1812-1814, 1392-1394, and 1972-1974. This mode will be referred to as the 'NS' mode, due to the north-south structure of the poles. These two millennium-scale modes (EC and NS) will guide the rest of our analyses herein. 

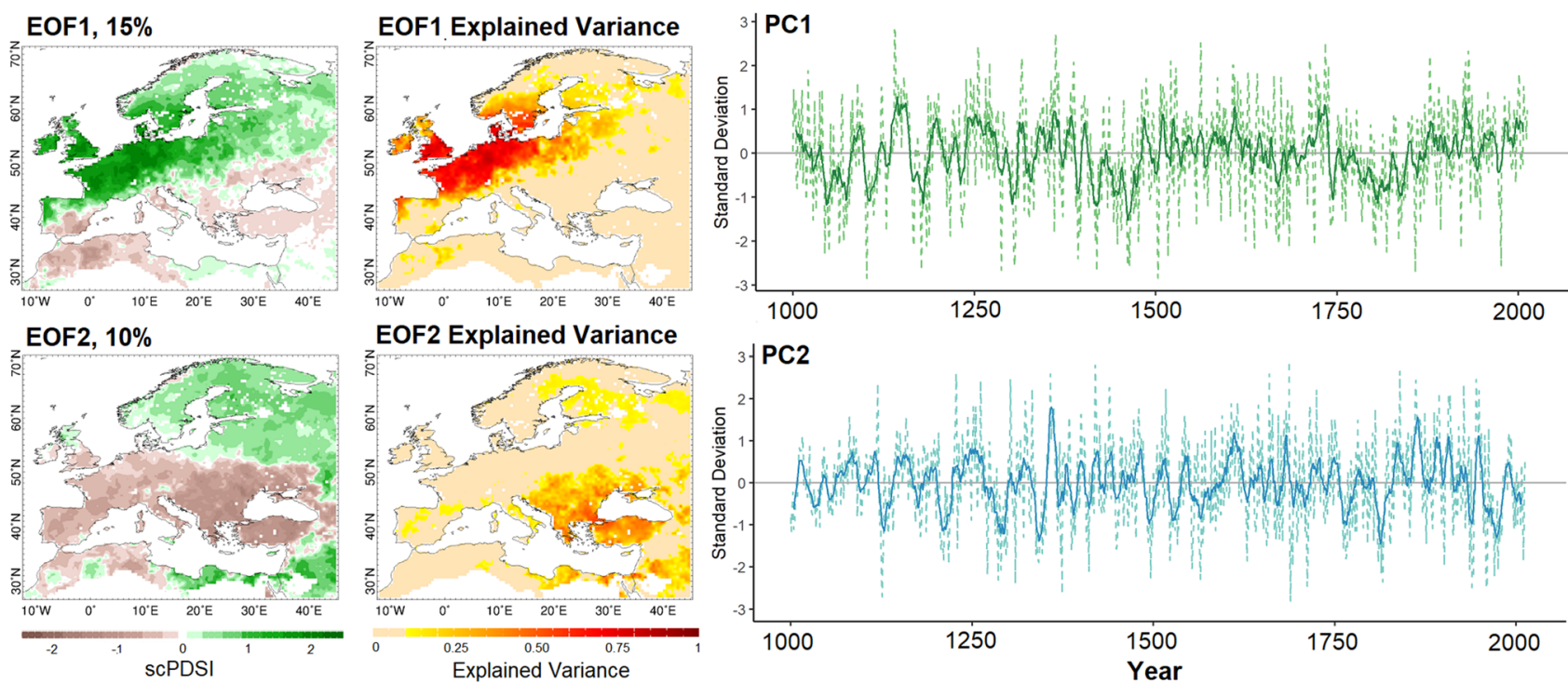

Fig. 2 First and second modes of the OWDA (1000-2012). Timeseries (PCs) are standardized, and the EOF maps present the value at +1 SD in scPDSI units. The first mode explains $15 \%$ of variance over the domain, the second mode explains $10 \%$ of the variance, though

\subsection{Leading modes of variability on a century-by-century basis}

While the EC mode dominates when evaluated over the entire millennium, it is possible that the NS mode or other patterns have more influence in some centuries or on shorter timescales. To examine this, we calculate the leading OWDA EOF for each century from 1000 to 2000 . The century mean locally the explained variances (shown in \%) are much higher. Timeseries show raw standard deviations (thin, dashed line) and centered 20-year moving averages (thick, solid line)

was removed and the data was detrended before performing the EOF analysis, in order to isolate the interannual to decadal variability. These results are shown in Fig. 3.

In most centuries, the leading mode has an anomaly centered over the area surrounding the English Channel, similar to the pattern observed in the long-term EC Mode. This pattern occurs as the leading mode in 9 of the 10 previous centuries. In the earliest centuries (1000-1100, 1100-1200,
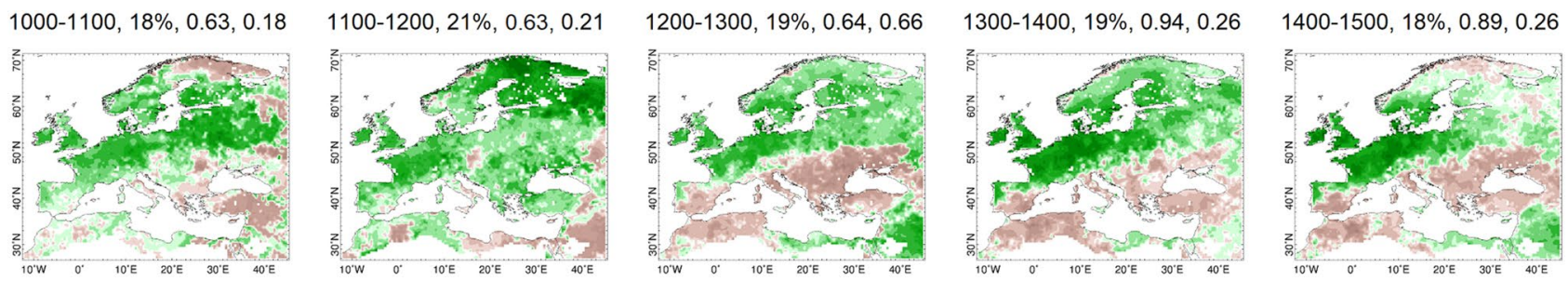

$1500-1600,16 \%, 0.90,0.04$
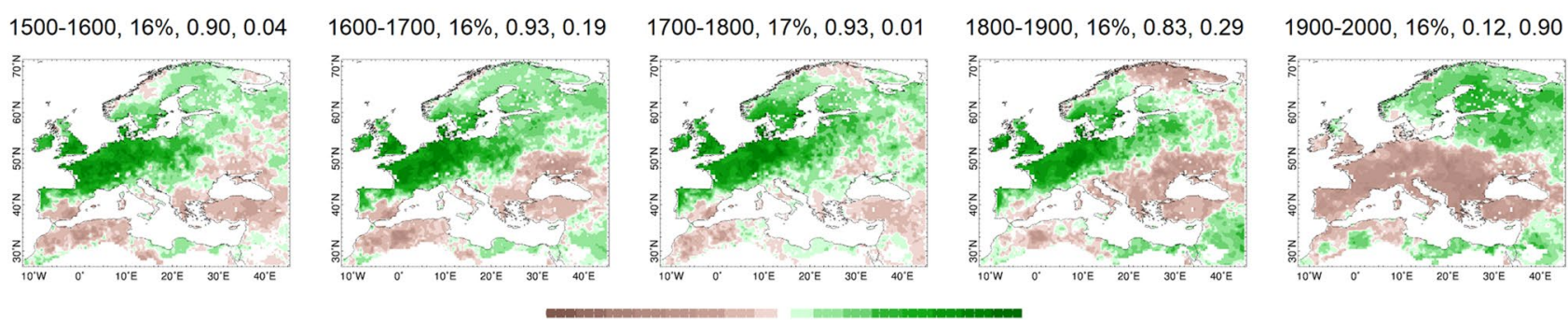

$-2$

ScPDSI

Fig. 3 Leading mode of OWDA for each century, from 1000 to 2000. Title headings show the century, the explained variance of the leading mode $(\%)$, and the absolute value of the pattern correlation between the mode and the long-term EOF1 (EC) and EOF2 (NS) modes 
and 1200-1300), the pattern correlation of the centuryscale leading mode with the millennium scale EC mode is $0.63,0.63$, and 0.64 , respectively, which is lower than in the later centuries. The century of 1200-1300 is unique, as the leading mode is correlated with both the EC mode (at 0.64 ) and the NS mode (at 0.66) equally, suggesting that the two influences may be mixed in the resulting pattern. In the subsequent centuries (from 1300 to 1800), the correlation of the leading mode with the EC mode becomes very high, near or above 0.90 , and the correlation with the NS mode is negligible. However, in 1900-2000 this pattern reverses, and the leading mode is very similar to the NS mode (correlation 0.89) rather than the EC mode (0.12). The first and second modes are statistically distinct in all centuries except 1800-1900, during which the modes were within error by 0.004 . The EC mode is clearly an important mode of summer surface hydroclimate variability in Europe across both interannual and centennial timescales, and the NS mode is only found to be dominant in the most recent century (1900-2000).

a. Correlation of 100-yr First Mode with EC, NS Modes

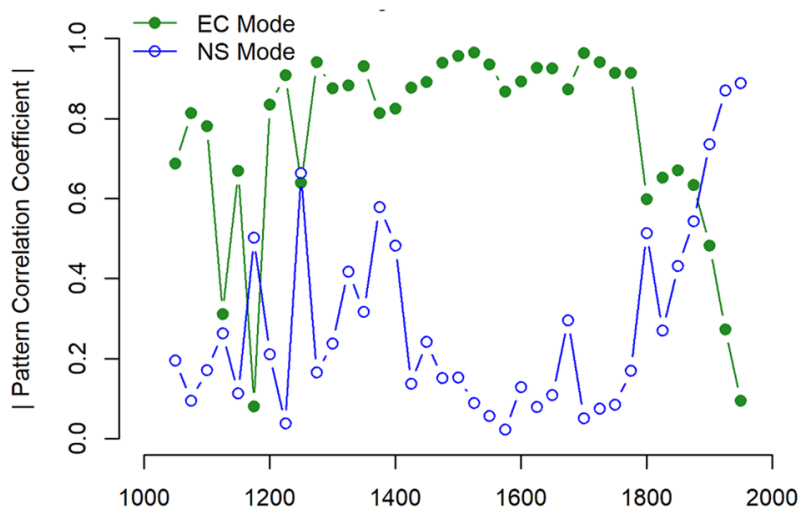

\subsection{Variations in the dominance and explained variance of the intra-century EC and NS modes over the last millennium}

To further investigate the intra-century modes and the modern switch to the NS mode seen in Fig. 3, we create a timeseries of pattern correlations between the century-scale OWDA modes and the millennium-scale EC and NS modes (Fig. 4). OWDA EOFs were calculated for a sliding 100year window, separated by 25 -year increments from 1000 to $1100,1025-1125$ and so on up to 1900-2000. Pattern correlations were then calculated between the century-scale leading mode and the EC and NS modes (defined as the first and second modes from 1000 to 2012). For most of the period, the century-scale leading mode of the OWDA is very similar to the EC mode (Fig. 4a). Although the 12th century mode shown in Fig. 3 has a correlation of 0.63 with the EC mode, other periods in that century show some lower correlations, such as 1125-1225 with a correlation of 0.08. Conversely, while the 1200-1300 century mode seems mixed (Fig. 3),

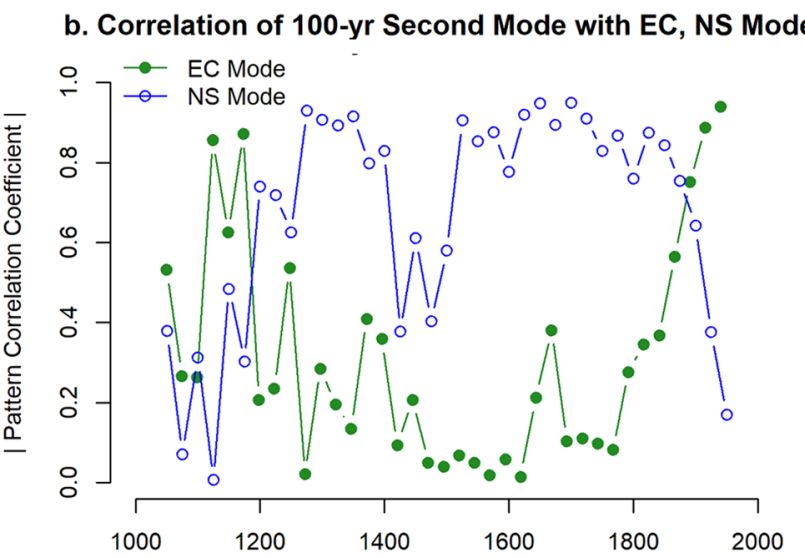

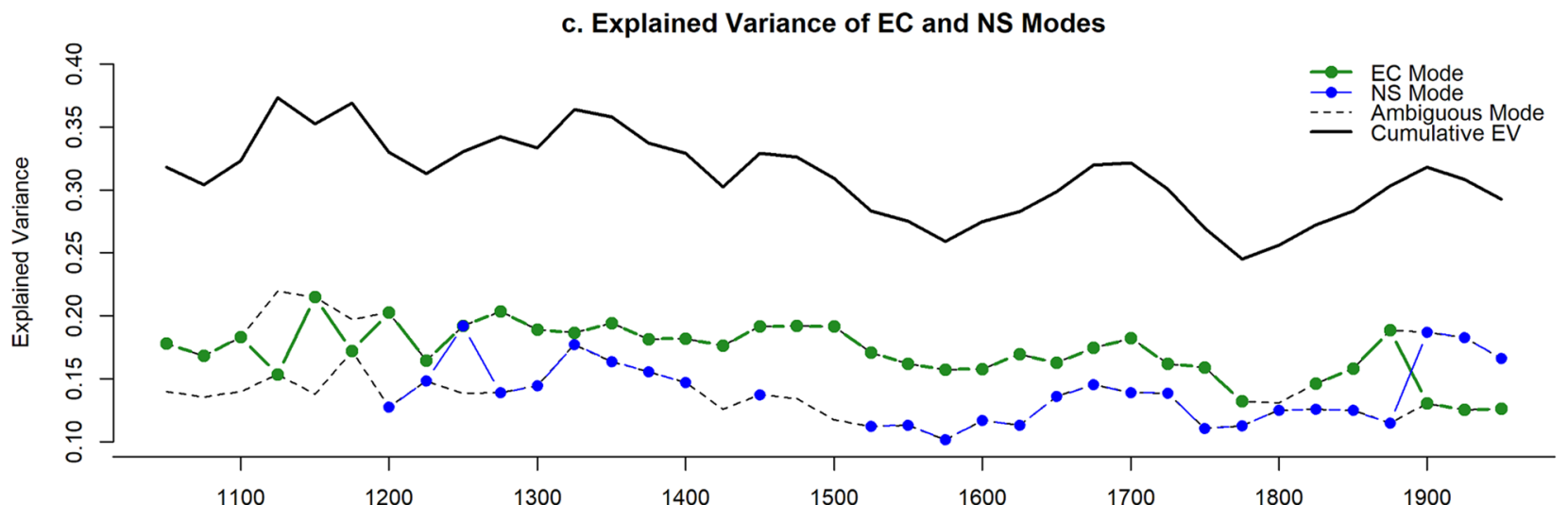

Fig. 4 Pattern correlation between the a leading and $\mathbf{b}$ secondary OWDA EOF for a 100-year sliding window and the millennium-scale (1000-2012) EC and NS modes. Points are plotted at the midpoint of each century. Pattern correlations are absolute values to allow for opposite sign EOFs of similar patterns. c Explained variance of the leading and secondary 100-year modes. Each mode was classified as either EC (green) or NS (blue) if the pattern correlation was $>0.6$, or ambiguous if not. Upper, thick black line shows the cumulative explained variance (EV) of the first and second modes together (EOF1 + EOF2 explained variances) 
other periods within that century show a stronger correlation with the EC mode, such as $1225-1325$ with a correlation of 0.94 . Beginning in $\sim 1800$, the correlation with the EC mode begins to decline, and the correlation with the NS mode rises. The most recent century is therefore a marked departure from the norm of the past millennium, which was primarily dominated by patterns similar to the EC mode.

To see if the EC and NS mode are simply swapping in order or if there are other modes present, the same analysis was conducted using the second mode of each 100-year period (Fig. 4b). This analysis shows a rough inverse of the correlation with the leading mode: when the correlation with the EC mode decreases in Fig. 4a, correlations increase with the NS mode in Fig. 4b. In the modern period, the leading mode becomes correlated with the NS mode and the second mode with the EC mode. This result indicates that the EC and NS modes are the leading modes in all periods, and are only varying as to which is leading and which is secondary.

This swap in leading and secondary mode does not necessarily imply any significant change in the variance explained. Both modes could potentially be explaining similar amounts of variance, and only swapping in dominance due to marginal changes. To see if this is the case, the explained variance of each century-scale mode was calculated. Combined with the information on the mode's spatial pattern correlation with the entire-millennium EC and NS modes, this allows us to plot the variance explained by the EC and NS modes of the OWDA over the last millennium (Fig. 4c). Modes with pattern correlation of $>0.6$ with the entiremillennium EC or NS modes were classified as the EC/NS mode (see Wilks (2011) for discussion on the 0.6 cutoff), while modes with $a<0.6$ pattern correlation to either the EC or NS were classified as ambiguous. We find that the EC mode has generally explained more variance over the past millennium than the NS mode. However, beginning around 1850, the modes switch in dominance, and the NS mode explains a higher amount of variance post-1850 than it previously had throughout the entire millennium (with the exception of a brief time in the mid 13th century). This 19th century switch therefore relates to notable changes in explained variance, and hence could represent real changes in the character of climate variability over the region.

\subsection{The modern wetting trend in England, Wales and northern continental Europe and relation to centennial variability of the EC mode}

To investigate how the change in dominant modes affects scPDSI, we calculate the difference in average scPDSI between two periods before and after the apparent switch: 1870-2010 and 1760-1869. The difference between these periods (Fig. 5a) shows a significant increase in average scPDSI in the region directly around the English Channel, in a spatial pattern that is similar to that of the EC mode. While this is partly by design due to how the periods were chosen for differencing, this shows a remarkable and regionally defined wetting of the $\mathrm{EC}$ region (defined here as $5^{\circ} \mathrm{W}-15^{\circ}$ E and $47^{\circ}-55^{\circ} \mathrm{N}$, black box labelled "EC Region"). Significant drying during this same period is only seen in some small pockets on the Iberian Peninsula, northern Africa, and Eastern Europe/Russia.

Instrumental records extending back before the 20th century are sparse, but those available do document a wintertime wetting trend in the EC region during the same time period. Historical rain gauge data from England and Wales (England and Wales Precipitation, EWP, Alexander and Jones 2000) show a significant $(p<0.05)$ upward trend in winter/ spring precipitation anomalies from 1766 to 2012 (Fig. 5b). Likewise, the vdS scPDSI (van der Schrier et al. 2013) also shows a significant increase in winter/spring scPDSI in the EC region through the 20th century. Both of these datasets support the findings from the OWDA that indicate a significant wetting trend in this region over the late 19th and 20th centuries. Also supporting the wintertime wetting trend are rain gauges and river flow records from Paris and northern France (Slonosky 2002; Dieppois et al. 2013, 2016).

The correlation of OWDA scPDSI in the EC region and the instrumental winter/spring vdS scPDSI in their overlap period (1901-2012) is 0.64, even though the vdS timeseries only includes winter/spring values, as opposed to the more summer-focused OWDA. The vdS PDSI in spring/summer shows no significant wetting trend, though the correlation with the OWDA is higher $(\mathrm{r}=0.83)$, consistent with OWDA targeting summer scPDSI (Cook et al. 2015). This further shows that the OWDA is recording both summer and winter hydroclimate, given strong correlations with both winter/ spring and spring/summer instrumental scPDSI.

Correlation of OWDA scPDSI values with winter/spring EWP is significant, but low $(r=0.30, n=247, p<0.05)$, which is expected because the OWDA scPDSI is influenced by both temperature and precipitation in the winter through summer. However, there is also a significant correlation $(\mathrm{r}=0.54)$ between the instrumental winter vdS scPDSI and the winter/spring EWP rain gauge timeseries in their overlap period. There is therefore a strong case that wintertime hydroclimate is influencing the tree-ring records that comprise the OWDA, and that the wet trend in the OWDA is related to the trend in winter precipitation seen in other datasets.

A long timescale examination of average OWDA scPDSI in the EC region over the past millennium (Fig. 5c) reveals a very strong correlation $(r=0.94)$ with the timeseries of the EC mode over the same period. Although some correlation with scPDSI is expected by design, as the EC region chosen has a high level of explained variance by the EC mode, this is still a particularly high correlation (Fig. 2). 

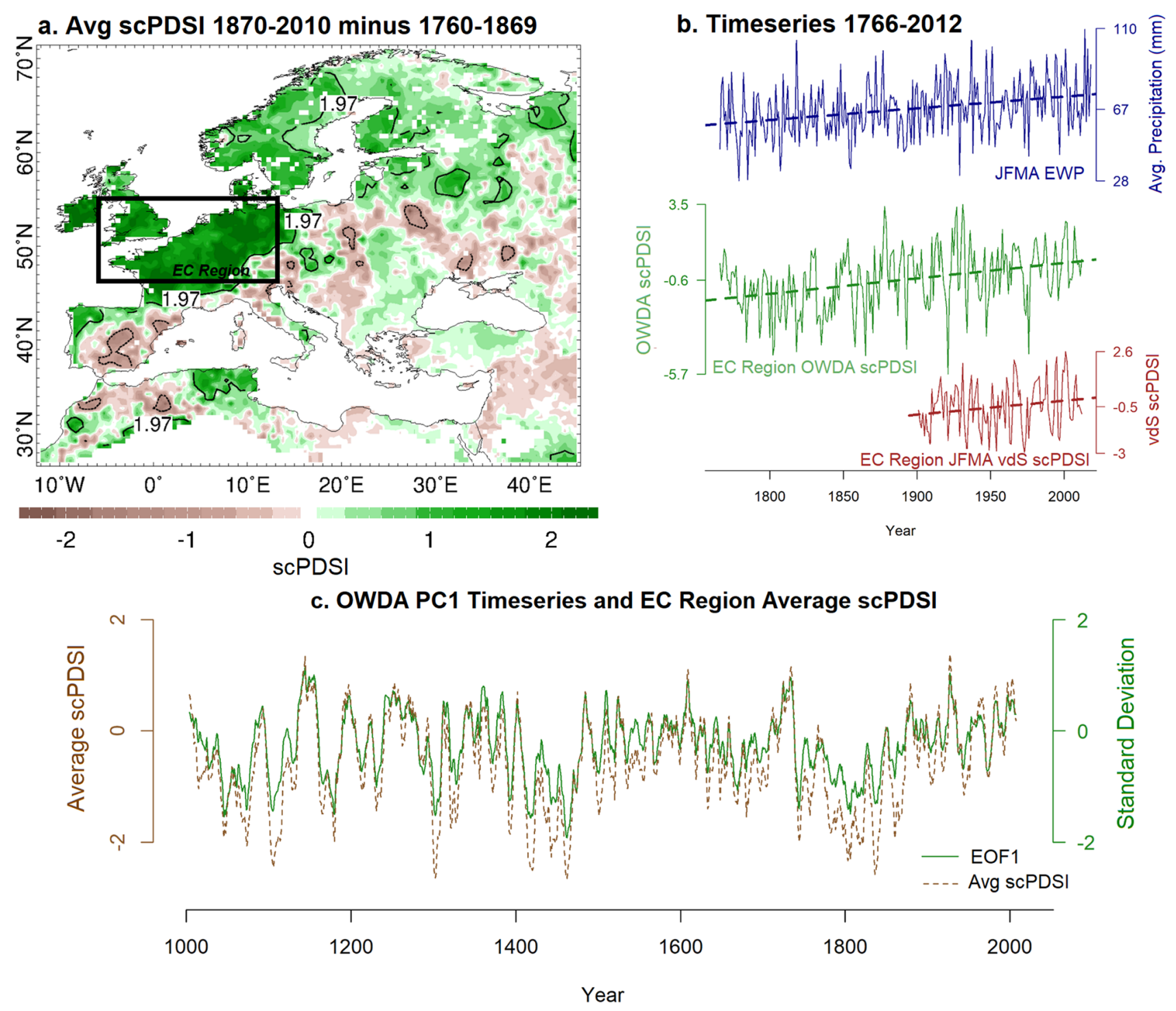

Fig. 5 Examination of a modern wetting trend in the EC region. a The difference in mean OWDA scPDSI (1870-2010 minus 1750$1869)$, showing an increase in average PDSI in the EC region. Results of a $t$-test show regions of significant differences $(t>1.97)$. b Timeseries showing the increase in winter precipitation, including histori- cal rain gauge data from England and Wales, average OWDA scPDSI in the EC region, and average instrumental winter/spring (JFMA) scPDSI from van der Schrier (vdS) in the EC region. c Average scPDSI in the EC region (right axis) and the PC1 timeseries of the OWDA (left axis) showing a strong correlation $(r=0.94)$
This indicates that this mode captures a dominant pattern in regional hydroclimate variation, and strongly suggests that the tree-ring records are capable of capturing century-scale variability.

\subsection{Linking the EC and NS modes to temperature, precipitation, atmospheric circulation and SSTs during the modern period}

In order to associate the EC and NS modes to physical climate, their variability over the modern period (1900-2010) is analyzed together with instrumental precipitation, surface temperature, and analyses of $500 \mathrm{hPa}$ heights and SSTs. Figure 6 shows the results of a correlation between the PC1 and PC2 timeseries and all individual precipitation and temperature grid points in both the winter/spring and spring/summer seasons. Notably, the EC mode (PC1) is strongly correlated with precipitation in northwestern Europe in both winter/spring and spring/summer. The EC mode is correlated with winter/spring temperatures on the Iberian Peninsula, in northern Africa, and the Balkans and Turkey, and with spring/summer temperatures in southern Italy, the Balkans, and Turkey. 

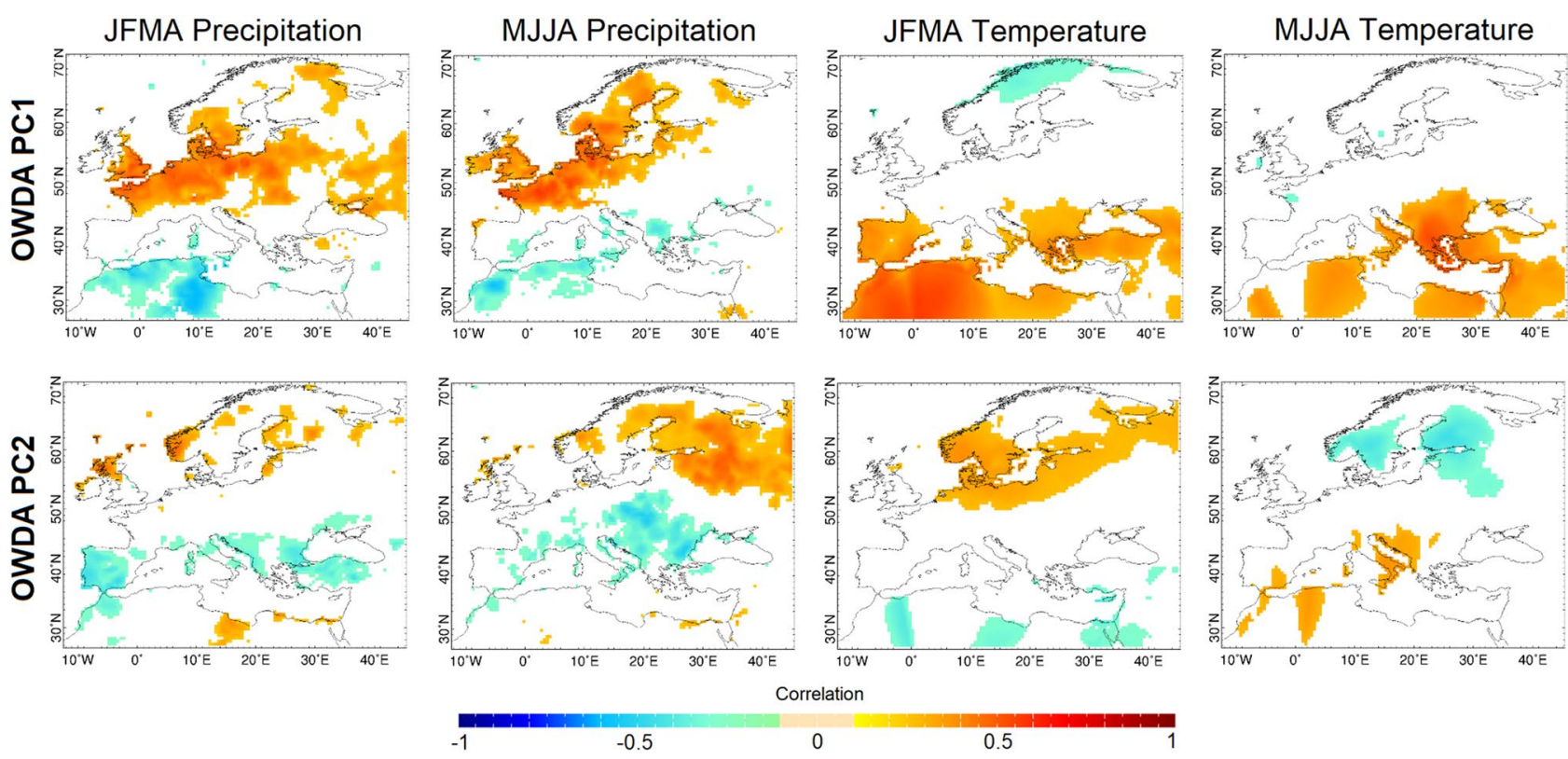

Fig. 6 Correlation of OWDA long-term PC1 (EC mode) and PC2 (NS mode) with instrumental precipitation and temperature, over the period 1950-2010. Correlation values are only shown above the 0.05 significance level

The NS mode (PC2) is negatively correlated with winter/ spring precipitation on the Iberian Peninsula and parts of southern Europe and Turkey. In spring/summer, the mode is positively correlated with precipitation in parts of Scandinavia, and negatively correlated with precipitation in parts of the Balkans and Eastern Europe. The NS mode is also correlated with temperature in Scandinavia in both seasons, though with opposite signs-positively in winter/spring, and negatively in spring/summer. For both the EC and NS modes, the correlations with temperature are regionally higher than for the OWDA in general (Fig. 1). This may be because the leading modes of the OWDA are physically realistic modes of large-scale climate variability, and therefore have more consistent relationships with temperature than the OWDA itself, which is also influenced by site-specific noise.

The two modes were also regressed with $500 \mathrm{hPa}$ geopotential heights and SSTs over two periods: 1901-1949 and 1950-2010 (Fig. 7). The later period corresponds to that of the CPC teleconnection indices (see Sect. 3.6) and the analysis for the earlier period provides a robustness check. SSTs are masked so that only significant $(\mathrm{p}<0.05)$ values are shown, and thick contours are plotted on top of the regression contours to show regions of significance with respect to the $500 \mathrm{hPa}$ heights.

The early period of winter/spring data does not show any regions of significant correlation with the EC mode (Fig. 7). In the modern period of winter/spring data, the EC mode is associated with low heights over the North Sea and Scandinavia, paired with another low off the eastern coast of North America. Significant positive correlations occur over
Greenland/Canada and likewise over the Iberian Peninsula and northern Africa.

In contrast to the winter/spring data, for spring/summer heights and SSTs there are significant correlations in both the early and later periods. The EC mode is associated with low heights over the North Atlantic-British Isles-North Sea region during both the early and later periods. In the early period (1901-1949), this is paired with a significant low over North America, while in the later period, this North American low is reduced in size and shifted northwards, and there are significant highs over Greenland and the portions of the Atlantic. In terms of wind direction, the EC mode is associated with stronger than normal westerly winds over central and Western Europe. These winds would bring moist marine air to the continent, consistent with the colocated wet anomaly in the EC spatial pattern (Fig. 2) and its expression in precipitation (Fig. 6). The SST anomalies are generally consistent with forcing by the atmosphere-for example, where the height anomalies would cause weaker wind speeds, the SST anomalies are warm (e.g. south of Greenland in spring/summer), and where they would create advection from warmer regions, the SST anomalies are also warm (e.g. west of the Iberian Peninsula and northern Africa in winter/spring).

Regression of the PC2 timeseries (the NS mode) with winter/spring heights for the same two periods shows a significant low centered over Greenland-Iceland and a high over the mid-latitude North Atlantic (Fig. 8), as well as stronger than normal marine air advection over Scandinavia. The SST anomalies are again consistent with atmospheric forcing, and 

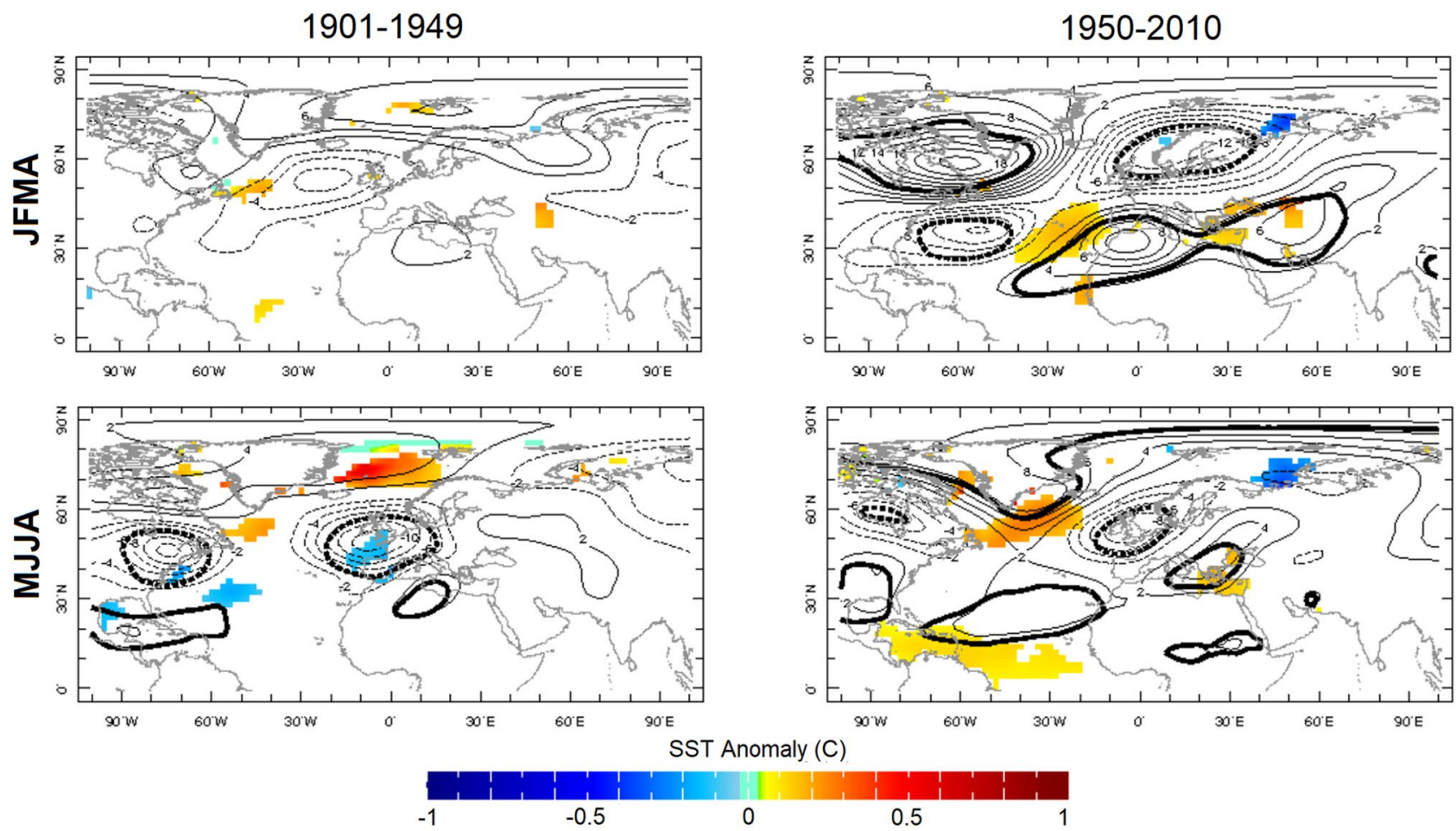

SST Anomaly (C)

Fig. 7 Regression of OWDA PC1 (EC mode timeseries) with winter/spring (JFMA) and spring/summer (MJJA) $500 \mathrm{hPa}$ geopotential heights (contours, bold where significant at the 0.05 level) and SSTs (colors over ocean where significant at 0.05 level) for two periods, 1900-1949 and 1950-2010. Contour interval for heights is $2 \mathrm{~m}$. Units are $\mathrm{m}$ and ${ }^{\circ} \mathrm{C}$ per standard deviation of the EOF time series (PC1)
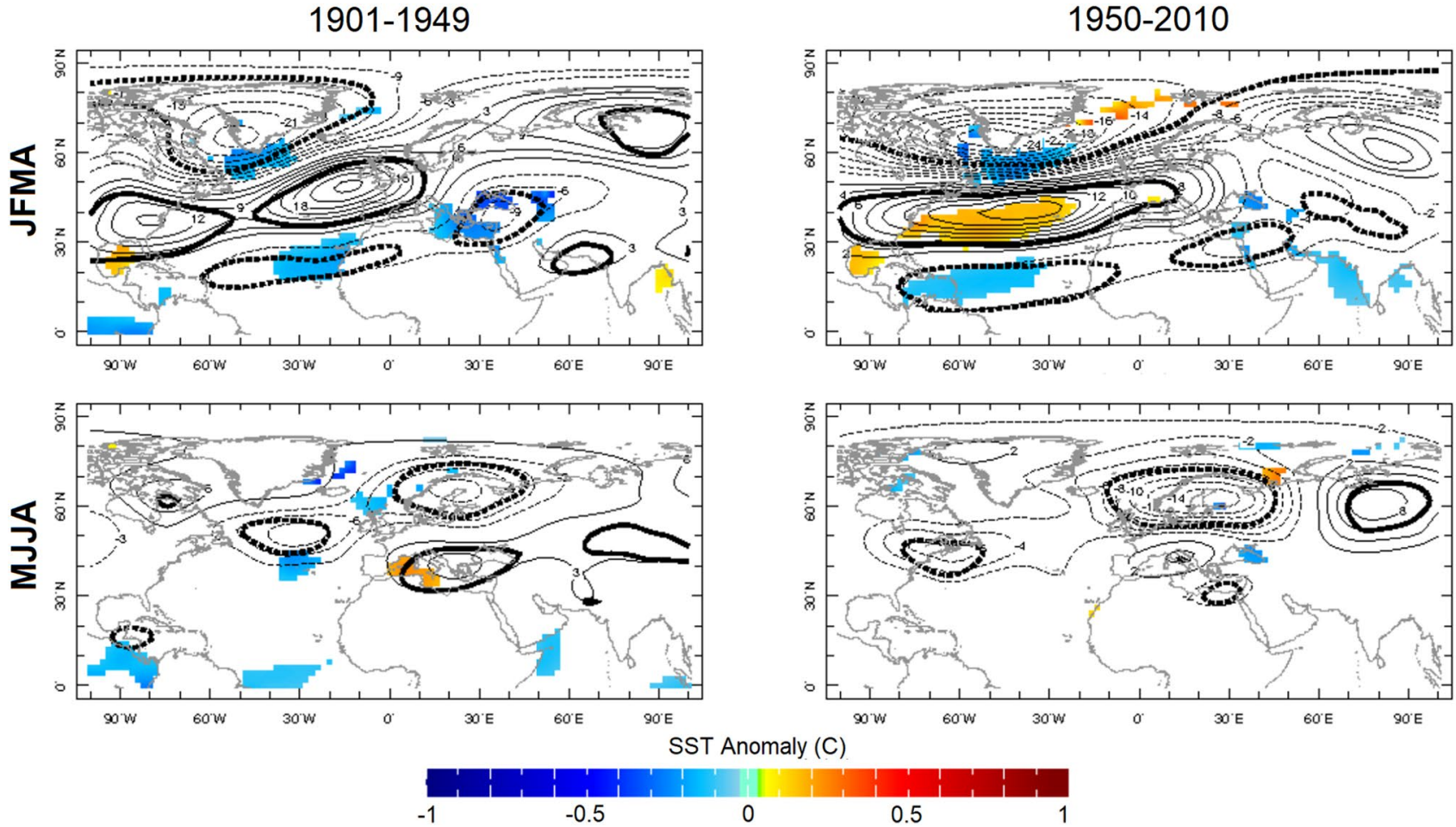

SST Anomaly (C)

$-0.5$

Fig. 8 Regression of OWDA PC2 (NS mode timeseries) with winter/spring (JFMA) and spring/summer (MJJA) $500 \mathrm{hPa}$ geopotential heights (contours, bold where significant at the 0.05 level) and SSTs (colors over ocean where significant at the 0.05 level). Contour interval for heights is $2 \mathrm{~m}$. Units are $\mathrm{m}$ and ${ }^{\circ} \mathrm{C}$ per standard deviation of the EOF timeseries (PC2) 
in the later period they show a characteristic tripole structure similar to that of the NAO (Seager et al. 2000). Performing the same regression with the NS mode and spring/summer heights and SSTs shows a pronounced low over Scandinavia, with another low over northeastern North America. The more recent period also shows a high over central Russia, east of the pronounced low over Scandinavia.

For both modes and seasons, given the limitations of the earlier data and with the exception of winter/spring for the EC mode, the patterns are broadly similar for the early and late 20th century, indicating some degree of robustness of the large-scale circulation variations associated with the modes.

\subsection{Relationship between the leading mode over the last millennium and known teleconnection patterns}

In order to compare the results from the EC and NS modes to those from known Northern Hemisphere teleconnections, we performed regressions of heights and SSTs for the 1950-2010 period with the CPC teleconnection indices of the East Atlantic (EA) pattern, the NAO, and the Scandinavian (SCA) pattern (Fig. 9). Regressions were performed for both winter and summer seasons.

The winter regression with the NAO has a pattern very similar to that of the NS mode in the winter (cf. Figs. 8 and 9). Over the period 1950-2010, the pattern correlation between the OWDA NS regression (Fig. 8) and the NAO regression (Fig. 9) is 0.96 for heights and 0.92 for SSTs. In contrast, the spring/summer regression of the NS mode is most similar that of the spring/summer Scandinavian index, with a pattern correlation of -0.89 for heights, though the pattern correlation with SSTs is much lower $(r=-0.33)$.

In contrast to the above results, the relation of the EC mode to known teleconnection patterns is far less clear. The modern winter/spring EC mode regression does not seem to be similar to any of the winter teleconnections: pattern correlations with the winter EA ( 0.20 heights, 0.07 SSTs $)$ and winter Scandinavian $(r=-0.16$ heights, -0.12 SSTs $)$ are low. Correlation with the winter NAO is higher $(r=-0.62$ heights, -0.62 SSTs). The East Atlantic teleconnection pattern in winter/spring (Fig. 9) bears a potential resemblance to the early period (1901-1949) winter EC Mode regression (Fig. 7), as both patterns show an elongated low in the northern Atlantic. However, this feature was not significant in the EC regression for that period. Turning to the spring/ summer relations, the regression between the EC mode and heights and SSTs has similarities to that of the spring/summer EA teleconnection (Fig. 6), with a negative pole over northwestern Europe and positive anomalies over the Balkans, though the pattern correlations are low $(r=0.55$ for heights, 0.22 for SSTs).

To examine the influence of these teleconnections on the OWDA itself, regressions and correlations were calculated between the CPC teleconnection indices and each point of the OWDA scPDSI (Fig. 10). The regression with the East Atlantic timeseries shows a pattern similar to the EC mode (Fig. 2) in both winter and summer. Pattern correlations between the EA regressions and the EC mode regression onto the OWDA for the same period are 0.57 for winter EA, and 0.82 for summer EA. The correlation
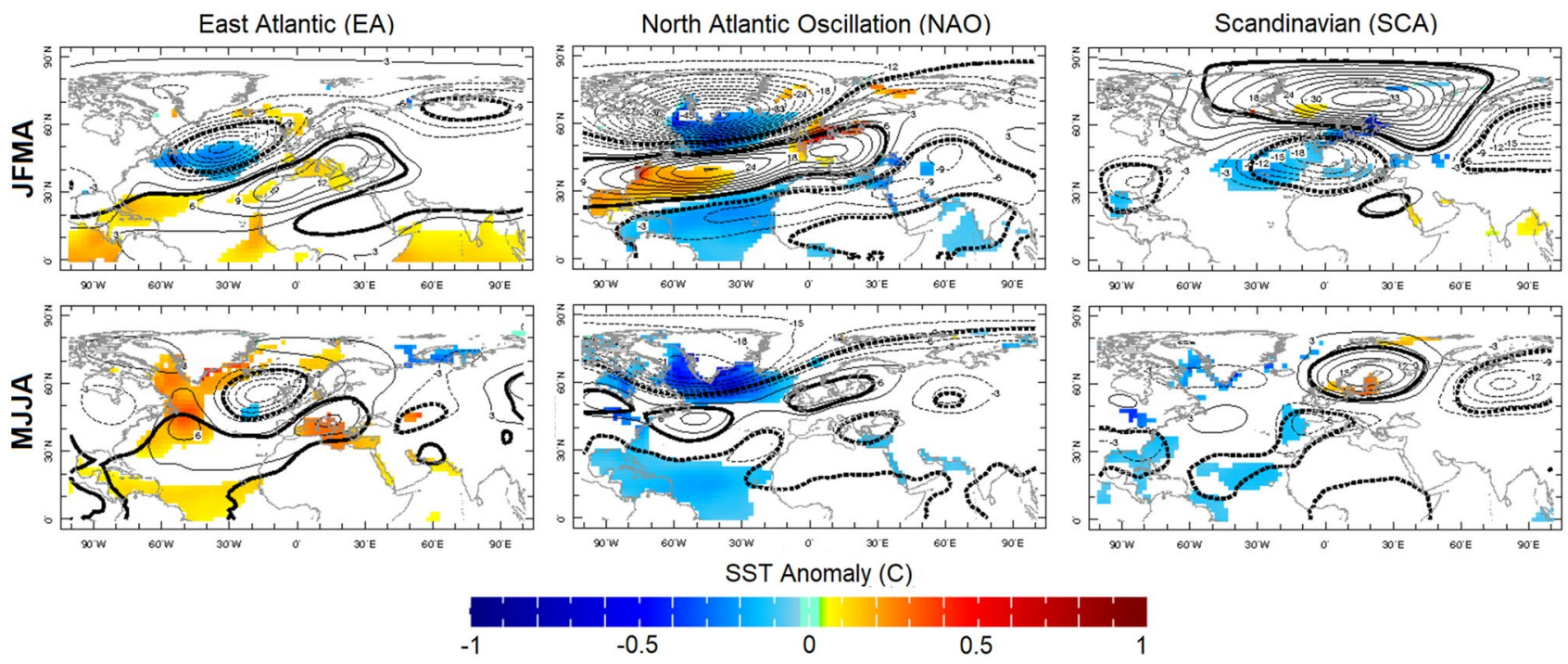

SST Anomaly (C)

Fig. 9 Regression of seasonal averages of CPC teleconnection indices with both winter/spring (upper row) and spring/summer (lower row) $500 \mathrm{mbar}$ geopotential heights (contours, bold where significant at the
0.05 level) and SSTs (colors over ocean where significant at the 0.05 level), 1950-2010. Units are $\mathrm{m}$ and ${ }^{\circ} \mathrm{C}$ per standard deviation of the teleconnection indices 

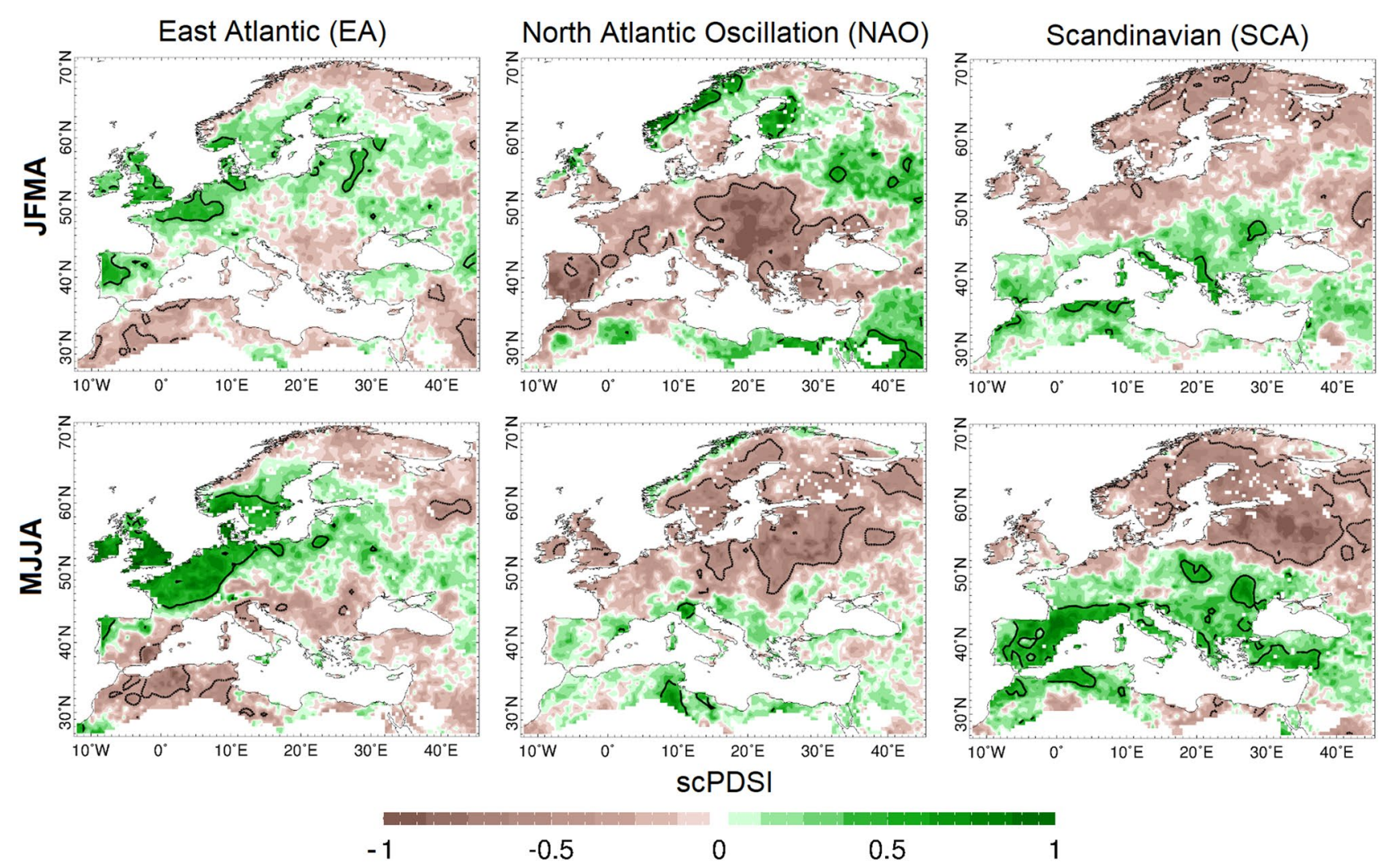

Fig. 10 Regression of seasonal CPC teleconnection indices with the raw OWDA data. Colors show regression (scPDSI per standard deviation of teleconnection index), contours show regions above the 0.05 significance level

between the EA index and the OWDA is significant across all of northwestern Europe in the summer, and is also significant in winter, though only in northern France and England.

In contrast to the EA, which has weak correlations with OWDA away from northwestern Europe, the winter/spring NAO is strongly negatively correlated to the OWDA scPDSI in the Balkans, Greece, and Turkey, as well as northern Africa, the Iberian Peninsula, and southern France (Fig. 10). Positive correlations are present in Norway, Finland and western Russia, and southern regions of the Levant. The pattern correlation between the regression of OWDA scPDSI with the winter/spring NAO and the NS Mode (Fig. 2) is 0.82. The Scandinavian pattern in winter/spring shows very few significant correlations, but in spring/summer it does have positive correlations with OWDA scPDSI along the Mediterranean, including southern France and the eastern Iberian Peninsula (this regression has a pattern correlation of -0.85 with the NS mode). Of the three prominent North Atlantic teleconnections, the EA pattern has the strongest expression in the OWDA scPDSI in the region of northwestern Europe centered over the English Channel.

\section{Discussion}

Several lines of evidence show that before 1850, the EC mode was a dominant driving pattern of European summer hydroclimate. The tight correlation between the EC mode timeseries and the average summer scPDSI in northwestern Europe (0.94, Fig. 5c) also establishes that there is a direct connection between the EC mode and regional moisture variability, as recorded by the OWDA. Over the late 19th century, this mode shifted from an extended period of negative values to varying around a state closer to neutrality, a shift that coincides with regional wetting. Given its close ties to average scPDSI in the EC region, it is likely that the modern wetting trend affecting northwestern Europe was associated with the decadal to centennial timescale variability of this mode. In addition to dominating the decadal-to-centennial variability in the European region, the EC pattern is also the leading pattern of interannual variability in most centuries of the last millennium.

Murphy et al. (2020) argue that the trend towards wetter winters in the England and Wales precipitation series (Wigley et al. 1984; Alexander and Jones 2000; Marsh 
et al. 2007) is the result of a data artifact, primarily the mismeasurement of snowfall totals in the early period. However, the wet winter trend is present in multiple other data sources. Independent rain gauges in Paris and northern France contain the trend (Dieppois et al. 2016; Slonosky 2002), as do river flow records from the Seine (Dieppois et al. 2016), which are not subject to the same snowfall measurement biases that can impact rain gauges. Additionally, the trend towards increasing scPDSI in northern Europe appears in the OWDA and also the instrumental vdS scPDSI in winter/spring (though it should be noted that the OWDA was calibrated on the vdS scPDSI, which is also partly dependent on rain gauge observations).

Because the OWDA targets growing season soil moisture availability, which is influenced by both precipitation and temperature from winter into summer, we cannot necessarily expect modes of variability revealed in the OWDA scPDSI to align with modern teleconnections defined in terms of monthly or seasonal circulation. Nonetheless, a large set of trees from the OWDA were found to be strong predictors of the winter NAO (Cook et al. 2019), showing that the OWDA can be used to study seasonally-specific phenomena. Our analysis found several similarities between the EC and NS modes and the EA and NAO teleconnections. The NS mode has an expression in heights and SSTs that is very similar to the NAO, with a pattern correlation of 0.95 for the NAO/ NS associated heights, and 0.91 for the associated SSTs. Additionally, the expression of the NS mode in scPDSI is similar to that of both the winter/spring NAO and the spring/ summer SCA index. While the atmospheric and SST expressions of the EC and EA modes are only somewhat similar in the summer $(\mathrm{r}=0.55$ heights, $0.22 \mathrm{SST}$ ) and nonexistent in the winter, the EA teleconnection index has an expression in scPDSI similar to the EC mode in both summer $(\mathrm{r}=0.82)$ and winter $(r=0.57)$ (Fig. 10), making it plausible that the two are dynamically related.

Analysis of modern precipitation variability in the British Isles shows that most wintertime variability is explained by a SLP mode very similar to the EA pattern, with a negative pole over the British Isles and the North Sea (Murphy and Washington 2001). Likewise, when direct rain gauge measurements from the EWP series are correlated with $500 \mathrm{hPa}$ heights in de Leeuw et al. (2015), they show a spatial pattern with a distinct anomaly over the EC area. Precipitation reconstructions find that extreme wet years in north-central Europe from 1500 to 2000 are associated with a strong anomaly in reconstructed SLP over the British Isles (Pauling et al. 2006). Reconstruction of historical SLP (Luterbacher et al. 2002) shows that while the first EOF of SLP from 1500 to 2000 more strongly resembles the NAO, the second EOF has a negative pole over the British Isles, more similar to the expression of the EC mode.
If the EC and NS modes are in fact related to the EA and NAO teleconnections, the changes in leading modes are particularly interesting, as they suggest that the NAO may not have had as much influence on European summer surface moisture variability in the past as it does today. The increase in the NS mode's dominance over summer surface moisture variability begins in roughly 1850 , concomitant with both the relative decline in importance of the EC mode and shift from a prolonged predominantly negative EC phase to a more neutral phase. Additionally, the change in average scPDSI in 100-year periods before and after 1870 has a spatial pattern similar to the EC mode, with significant differences in precipitation in France, southern England and Wales between the two periods (Fig. 5). We therefore propose that a shift in the EC mode from persistent negative values to more neutral values may be responsible for the modern wet shift in northwestern Europe. Speculatively (because of the absence of circulation data), this might be related, at least in part, to a similar shift in the EA teleconnection pattern. The winter CPC EA index has trended upwards significantly since 1950, a change that has been associated with both warmer and wetter winters in the British Isles (Conrad et al. 2003). Historical reconstruction of the EA index likewise shows an upward trend over the course of the 20th century, though not before (Mellado-Cano et al. 2019).

Despite our speculation, it still remains unclear what can cause such decadal to centennial variability in atmospheric teleconnections. Over the North Pacific, decadal shifts in circulation patterns such as the Pacific-North America pattern are related to Rossby wave teleconnections driven by decadal shifts in tropical SSTs (Graham 1994; Trenberth and Hurrell 1994), but there is little evidence for this process causing changes in circulation over the North Atlantic and Europe. Circulation over these sectors nevertheless does have impressive decadal and longer timescale variability. In this regard, the decadal variability of both the EA and the NAO are yet to be fully explained (Osborn 2011; Scaife et al. 2014; Mellado-Cano et al. 2019; Seager et al. 2020). It therefore is somewhat unsurprising that European hydroclimate has large decadal and longer timescale variability, but the dynamical origins of this variability remain a mystery, despite its potent influence on regional climate.

\section{Conclusions}

The wet trend in northern European hydroclimate over the last 150 years is related to the fluctuations and changes in dominance of the EC hydroclimate mode during the same period. This mode has a similar expression in scPDSI to that of the modern East Atlantic teleconnection. In contrast, the second hydroclimate mode of the OWDA, the NS mode, has a similar expression to that of the NAO. For most of 
the last millennium the EC mode was the leading mode of variability in tree-ring derived scPDSI. The NS mode is the leading mode only in the recent period, which may suggest that the modern prominence of the NAO as a control on European summer surface moisture variability is relatively new. However, more study is needed to work out the connections between these observed hydroclimate modes of reconstructed summer scPDSI and teleconnection patterns in the North Atlantic and European region.

Acknowledgements S. Scholz, R. Seager, Y, Kushnir, and E. Cook were supported by NSF AGS-1734760. B. I. Cook was supported by the NASA Modeling, Analysis, and Prediction program. M. Ting was supported by NSF AGS-1934358. S. H. Baek was supported by the Flint Postdoctoral Fellowship at Yale University. S. Scholz would like to thank the Lamont-Doherty Summer Intern Program.

Funding S. Scholz, R. Seager, Y, Kushnir, and E. Cook were supported by NSF AGS-1734760, B. I. Cook was supported by the NASA Modeling, Analysis, and Prediction program, M. Ting was supported by NSF AGS-1934358, S. H. Baek was supported by the Flint Postdoctoral Fellowship at Yale University.

Availability of data and material All datasets used are freely available and can be found online. The OWDA can be found at: https://www. ncdc.noaa.gov/paleo-search/study/19419.

Code availability Please contact S. Scholz for code.

\section{Declarations}

Conflict of interest The authors declare that they have no conflict of interest statement.

\section{References}

Alexander LV, Jones PD (2000) Updated precipitation series for the UK and discussion of recent extremes. Atmos Sci Lett 1:1530-1261X

Anderson W, Seager R, Baethgen W, Cane M (2019) Synchronous crop failures and climate-forced production variability. Sci Adv 5:eaaw1976. https://doi.org/10.1126/sciadv.aaw1976

Baek SH, Smerdon JE, Coats S, Williams AP, Cook BI, Cook ER, Seager R (2017) Precipitation, temperature, and teleconnection signals across the combined North American, Monsoon Asia, and old world drought atlases. J Clim 30:7141-7155. https://doi.org/ 10.1175/JCLI-D-16-0766.1

Baek SH, Smerdon J, Dobrin G-C, Naimark J, Cook ER, Cook BI, Seager R, Cane M, Scholz SR (2020) A quantitative hydroclimatic context for the European Great Famine of communications. Earth Environ 1:1315-1317. https://doi.org/10.1038/ s43247-020-00016-3

Cassou C, Terray L, Deser C (2004) North Atlantic winter climate regimes: spatial asymmetry, stationarity with time oceanic forcing. J Clim 17:1055-1068

Compo GP et al (2011) The twentieth century reanalysis project. Q J R Meteorol Soc 137:1-28. https://doi.org/10.1002/qj.776

Conrad KF, Woiwod IP, Perry JN (2003) East Atlantic teleconnection pattern and the decline of a common arctiid moth. Glob Change Biol 9:125-130. https://doi.org/10.1046/j.1365-2486. 2003.00572.x
Cook ER et al (2015) Old World megadroughts and pluvials during the Common Era. Sci Adv 1:e1500561. https://doi.org/10.1126/ sciadv. 1500561

Cook ER, Jacoby GC (1977) Tree-ring-drought relationships in the Hudson Valley,\&nbsp;New York. Science 198(4315):399-401. https://doi.org/10.1126/science.198.4315.399

Cook ER, Kushnir Y, Smerdon JE, Williams AP, Anchukaitis KJ, Wahl ER (2019) A Euro-Mediterranean tree-ring reconstruction of the winter NAO index since 910 CE. Clim Dyn 53:15671580. https://doi.org/10.1007/s00382-019-04696-2

Cook ER, Seager R, Cane MA, Stahle DW (2007) North American drought: Reconstructions, causes, and consequences. Earth Sci Rev 81(1-2):93-134. https://doi.org/10.1016/j.earscirev.2006. 12.002

Cook BI, Mankin JS, Marvel K, Williams AP, Smerdon JE, Anchukaitis KJ (2020) Twenty-first century drought projections in the CMIP6 forcing scenarios. Earth's Future. https://doi.org/ 10.1029/2019EF001461

Cotterill D, Stott P, Christidis N, Kendon E (2021) Increase in the frequency of extreme daily precipitation in the United Kingdom in autumn. Weather Clim Extremes 33:100340. https://doi.org/ 10.1016/j.wace.2021.100340

Cullen HM, Kaplan A, Arkin PA, deMenocal PB (2002) Impact of the North Atlantic influence on Middle Eastern climate and streamflow. Clim Change 55:315-338. https://doi.org/10. 1023/A:1020518305517

de Leeuw J, Methven J, Blackburn M (2015) Variability and trends in England and Wales precipitation. Int J Climatol 36:2823-2836

Dieppois B, Durand A, Fournier M, Massei N (2013) Links between multidecadal and interdecadal climatic oscillations in the North Atlantic and regional climate variability of northern France and England since the 17th century. J Geophys Res Atmos 118:4359-4372

Dieppois B, Lawler DM, Slonosky V, Massei N, Bigot S, Fournier M, Durand (2016) Multidecadal climate variability over northern France during the past 500 years and its relation to large-scale atmospheric circulation. Int J Climatol 36:4679-4696. https:// doi.org/10.1002/joc. 4660

Dommenget D, Latif M (2002) A cautionary note on the interpretation of EOFs. J Clim 15(2):216-225. https://doi.org/10.1175/ 1520-0442(2002)015<0216:ACNOTI >2.0.CO;2

Fye FK, Stahl DW, Cook ER (2003) Paleoclimatic analogs to twentieth-century moisture regimes across the United States. Bull Am Meteorol 84:901-910

Graham NE, Barnett TP, Wilde R, Ponater M, Schubert S (1994) On the roles of tropical and midlatitude SSTs in forcing interannual to interdecadal variability in the Winter Northern Hemisphere circulation. J Clim 7:1416-1441

Hall JW, Sayers PB, Dawson RJ (2005) National-scale assessment of current and future flood risk in England and Wales. Nat Hazards 36:147-164. https://doi.org/10.1007/s11069-004-4546-7

Harris IC, Jones PD (2017) CRU TS3.25: Climatic Research Unit (CRU) Time-Series (TS) Version 3.25 of High-Resolution Gridded Data of Month-by-month Variation in Climate (Jan. 1901Dec. 2016). Centre for Environmental Data Analysis. https:// doi.org/10.5285/c311c7948e8a47b299f8f9c7ae6cb9af

Huang B, Thorne PW et al (2017) Extended reconstructed sea surface temperature version 5 (ERSSTv5), upgrades, validations, and intercomparisons. J Clim. https://doi.org/10.1175/ JCLI-D-16-0836.1

Hurrell JW (1995) Decadal trends in the North-Atlantic Oscillationregional temperatures and precipitation. Science 269:676-679

Hurrell JW, Deser C (2009) North Atlantic climate variability: the role of the North Atlantic Oscillation. J Mar Syst 78:28-41

Krichak SO, Breitgand JS, Gualdi S, Feldstein SB (2014) Teleconnection-extreme precipitation relationships over the Mediterranean 
region. Theor Appl Climatol 117:679-692. https://doi.org/10. 1007/s00704-013-1036-4

Luterbacher J, Xoplaki E, Dietrich D et al (2002) Reconstruction of sea level pressure fields over the Eastern North Atlantic and Europe back to 1500. Climate Dynamics 18:545-561. https://doi.org/10. 1007/s00382-001-0196-6

Madakumbura GD, Kim H, Utsumi N, Shiogama H, Fischer EM, Seland Ø, Scinocca JF, Mitchell DM, Hirabayashi Y, Oki T (2019) Event-to-event intensification of the hydrologic cycle from $1.5^{\circ} \mathrm{C}$ to a $2{ }^{\circ} \mathrm{C}$ warmer world. Sci Rep 9:3483. https://doi.org/10.1038/ s41598-019-39936-2

Markonis Y, Hanel M, Máca P, Kyselý J, Cook ER (2018) Persistent multi-scale fluctuations shift European hydroclimate to its millennial boundaries. Nat Commun 9:1767. doi:https://doi.org/10. 1038/s41467-018-04207-7

Marsh T, Cole G, Wilby R (2007) Major droughts in England and Wales, 1800-2016. Weather 62:87-93

Mellado-Cano J, Barriopedro D, Garcia-Herrera R, Trigo RM, Hernandez A (2019) Examining the North Atlantic Oscillation, East Atlantic pattern, and jet stream variability since 1685 . J Clim 32:6285-6298. https://doi.org/10.1175/JCLI-D-19-0135.1

Murphy SJ, Washington R (2001) United Kingdom and Ireland precipitation variability and the North Atlantic sea-level pressure field. Int. J. Climatol. 21:939-959. https://doi.org/10.1002/joc.670

Murphy C et al (2020) Multi-century trends to wetter winters and drier summers in the England and Wales precipitation series explained by observational and sampling bias in early records. Int J Clim 40:610-619. doi:https://doi.org/10.1002/joc.6208

North GR, Bell TL, Cahalan RF, Moeng FJ (1982) Sampling errors in the estimation of empirical orthogonal functions. Mon Weather Rev 110:199-706. https://doi.org/10.1175/1520-0493(1982)110< 0699:SEITEO > 2.0.CO;2

Osborn TJ (2011) Variability and changes in the North Atlantic Oscillation index. In: Vicente-Serrano S, Trigo R (eds) Hydrological, socioeconomic and ecological impacts of the North Atlantic oscillation in the Mediterranean Region. Springer, Berlin, pp 9-22

Posthumus H, Morris J, Hess TM, Neville D, Phillips E, Baylis A (2009) Impacts of the summer 2007 floods on agriculture in England. J Flood Risk Manag 2:182-189

Scaife A et al (2014) Skillful long-range prediction of European and North American winters. Geophys Res Lett 41:2514-2519. https://doi.org/10.1002/2014GL059637

Seager R, Kushnir Y, Visbeck M, Naik N, Miller J, Krahmann G, Cullen H (2000) Causes of Atlantic Ocean Climate Variability between 1958 and 1998. J Clim 13(16):2845-2862. https://doi. org/10.1175/15200442(2000)013<2845:COAOCV > 2.0.CO;2
Seager R, Kushnir Y, Nakamura J, Ting M, Naik N (2010) Northern Hemisphere winter snow anomalies: ENSO, NAO and the winter of 2009/10. Geophys Res Lett. https://doi.org/10.1029/2010G L043830

Seager R, Osborn TJ, Kushnir Y, Simpson IR, Nakamura J, Liu H (2019) Climate variability and change of Mediterraneantype climates. J Clim 32:2887-2915. https://doi.org/10.1175/ JCLI-D-18-0472.1

Seager R, Liu H, Kushnir Y, Osborn TJ, Simpson IR, Kelley CR, Nakamura J (2020) Mechanisms of Winter precipitation variability in the European-Mediterranean region associated with the North Atlantic oscillation. J Clim 33:7179-7196. https://doi.org/10. 1175/JCLI-D-20-0011.1

Sheffield J, Wood EF (2008) Global trends and variability in soil moisture and drought characteristics, 1950-2000, from observationdriven simulations of the terrestrial hydrologic cycle. J Clim 21:432-458. https://doi.org/10.1175/2007JCLI1822.1

Slonosky VC (2002) Wet winters, dry summers? Three centuries of precipitation data from Paris. Geophys Res Lett 19:1895. doi:https://doi.org/10.1029/2001GL014302

Trenberth KE, Hurrell JW (1994) Decadal atmosphere-ocean variations in the Pacific. Clim Dyn 9:303-319

Trigo IF, Pozo-Vazquez D, Osborn TJ, Castro-Diez Y, Gamiz-Fortis S, Esteban Parra MJ (2004) North Atlantic Oscillation influence on precipitation, river flow and water resources in the Iberian Peninsula. Int J Climatol 24:925-944. https://doi.org/10.1002/joc.1048

van der Schrier G, Barichivich J, Briffa KR, Jones PD (2013) A scPDSI-based global data set of dry and wet spells for 1901-2009: variations in the self-calibrating PDSI. J Geophysl Res Atmos 118:4025-4048. https://doi.org/10.1002/jgrd.50355

Wells N, Goddard S, Hayes MJ (2004) A self-calibrating palmer drought severityindex. J Clim 17:2335-2351

Wigley TML, Lough JM, Jones PD (1984) Spatial patterns of precipitation in England and Wales and a revised, homogenous England and Wales precipitation series. J Clim 4:1-25

Wilks DS (2011) Statistical methods in the atmospheric sciences, 3rd edn. Academic Press, Oxford

Publisher's Note Springer Nature remains neutral with regard to jurisdictional claims in published maps and institutional affiliations. 